\title{
Abordaje del diseño bioinspirado en las formas, los sistemas y los procesos de la naturaleza
}

\section{Approach to bioinspired design in the forms, systems and processes of nature}

Daniel Edgardo Vedoya

Profesor Titular de Construcciones II y Estructuras III; Director del Instituto de Investigaciones Tecnológicas para el Diseño Ambiental del Hábitat Humano, Facultad de Arquitectura y Urbanismo, Universidad Nacional del Nordeste, Resistencia (del Chaco, Argentina

devedoya@gmail.com

\section{RESUMEN}

Sería interminable hablar de las formas, los sistemas y los procesos que se presentan en cualquier recodo de la naturaleza.

Podemos encarar el estudio de la naturaleza desde cualquiera de estos ejes fundamentales: las formas, los sistemas o los procesos.

Lo que no podremos, cualquiera sea el eje que seleccionemos, será prescindir de transitar por los otros dos.

Formas, sistemas y procesos son tres factores naturales independientes, pero íntimamente implicados unos en los otros, que interactúan entre sí, y que se dan razón de ser mutuamente.

\section{ABSTRACT}

It would be endless to talk about the forms, systems and processes that occur in any corner of nature.

We can approach the study of nature from any of these fundamental axes: forms, systems or processes.

What we will not be able to, whatever the axis we select, will be to dispense with the other two. Forms, systems and processes are three independent natural factors, but intimately involved in each other, interacting with each other, and giving each other a reason for being.

PALABRAS CLAVE: Ecosistemas - Diseño biomimético - Leyes de distribución

KEYWORDS: Ecosystems - Biomimetic design - Distribution laws

FECHA DE RECEPCIÓN: 17/8/2021| FECHA DE ACEPTACIÓN: 11/10/2021

DOI: http://dx.doi.org/10.30972/arq.0185669 


\section{INTRODUCCIÓN}

El Universo se nos presenta de variadas maneras: formas, tamaños, colores, texturas, aromas, etc. La relación del ser humano con la realidad exterior se realiza por medio de sensaciones visuales, táctiles, olfativas, auditivas, etc.; esa percepción a través de los sentidos es asociativa aunque en el ser humano es fácilmente comprobable la preeminencia de las percepciones canalizadas por medios visuales.

Una forma es inherente a una determinada cosa, es aquello que conocemos de la cosa en primera instancia, lo observable, lo que percibimos a través de los sentidos. La forma es la manera como los objetos se presentan ante el sujeto, es un hecho de base visual, lo que implica el empleo de todos los sentidos coordinados por la vista, que estructura y orienta los datos provistos por los demás sentidos. El primer conocimiento formal que tenemos de una cosa es siempre sensorial y no inteligente.

Luego se producen los procesos intelectuales y es cuando comenzamos a comprender eso que hemos percibido.

La pompa de jabón (Figura 1) es el resultado del equilibrio entre dos fuerzas opuestas. Por un lado, la presión del aire contenido en su interior, que pugna por expandirse, y por el otro, la presión atmosférica que se opone y tiende a aplastar la pompa.

En el medio, la membrana jabonosa, cuya forma es la de una esfera perfecta, se convierte en el límite que separa estas dos tensiones, y determina la superficie mínima necesaria y suficiente para contener el volumen de aire en su interior. Cualquier otro recipiente que contenga el mismo volumen de aire y cuya forma no sea esférica, indefectiblemente necesitará mayor superficie que la de la pompa.

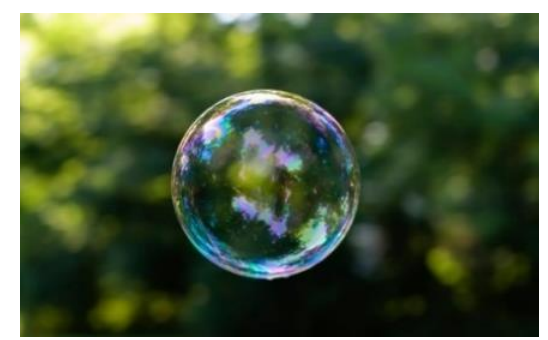

Figura 1: Una pompa de jabón en el espacio. Fuente: Producción propia

Al apoyar esa misma pompa sobre una superficie plana, inmediatamente se convertirá en una semi esfera perfecta, como lo demuestra la imagen (Figura 2).

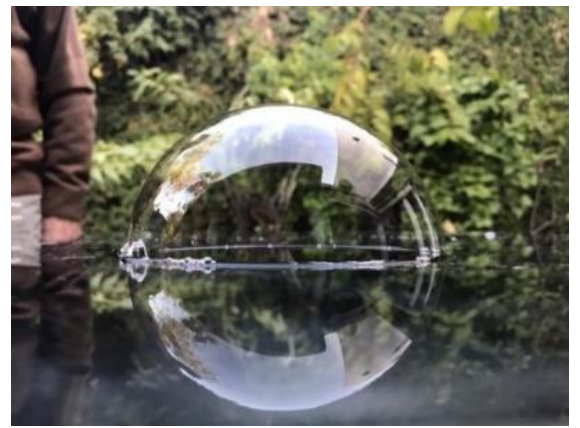

Figura 2: Pompa apoyada sobre una superficie plana horizontal. Fuente: Producción propia

Al analizar una pompa de jabón, se descubrirá que en ella se cumplen las dos leyes básicas fundamentales de la naturaleza: de economía de la sustancia y del mínimo esfuerzo. 
Vedoya

Ahora, al anexar dos pompas entre sí, inmediatamente se deformarán definiendo una pared que las separa, que será plana o curva según estas pompas sean iguales o de diferente tamaño (Fig. 3). Lo mismo pasará cuando se anexe una tercera pompa (Fig. 4), y luego una cuarta (Fig. 5).

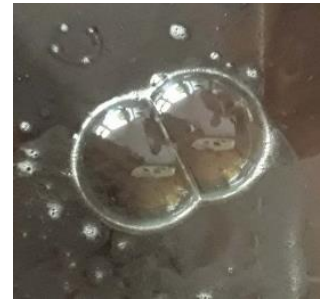

Figura 3: Dos pompas anexadas

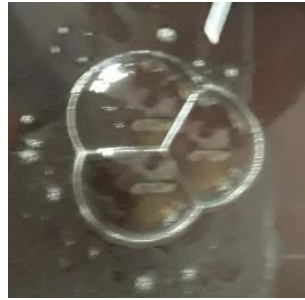

Figura 4: Tres pompas anexadas Fuente: Producción propia

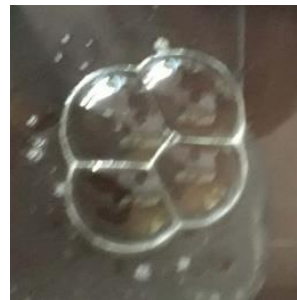

Figura 5: Cuatro pompas anexadas

Aquí se comprueba una vez más la presencia de las dos leyes mencionadas.

\section{DESARROLLO}

Si se observa en detalle el límite entre estas pompas, se comprobará que en ninguno de estos casos concurren más de tres en el encuentro, debido a que en este punto se produce una distribución tensional en tres direcciones.

Este fenómeno se puede aplicar cuando se trata de encontrar el menor recorrido entre tres (Figura 6), cuatro (Figura 7), cinco (Figura 8), y no importa cuántos puntos sean, distantes unos de otros.

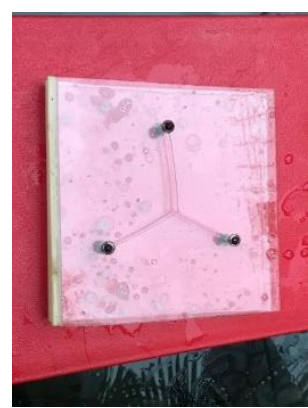

Figura 6: Distancia entre 3 puntos

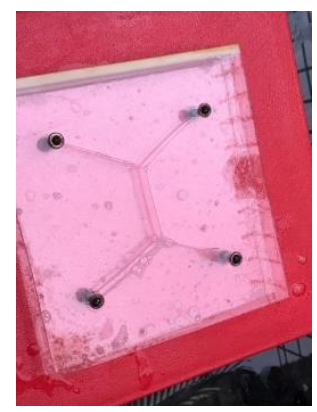

Figura 7: Distancia entre 4 puntos

Fuente: Producción propia

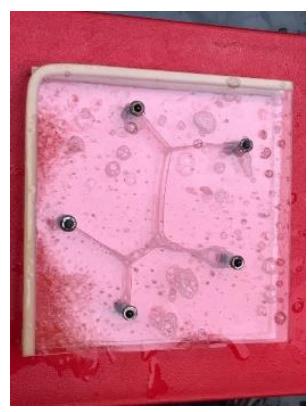

Figura 8: Distancia entre 5 puntos

Esto que se vio hasta acá confirma el Teorema de Fermat, también conocido como "Punto de Fermat", que propone que en todo triángulo siempre habrá un punto interior, y sólo uno, por el que pasará el recorrido menor que una con dicho punto los vértices del triángulo considerado. En la siguiente imagen (Figura 9) se comprueba una nueva convención, constante en toda distribución espacial existente en la naturaleza. Dado un conjunto de pompas en el espacio, a cada arista concurrirán sólo tres superficies o caras, y a cada vértice concurrirán sólo cuatro aristas.

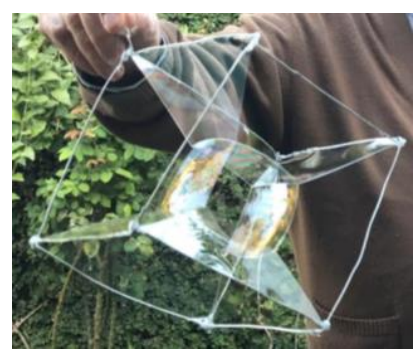

Figura 9: Concurrencia de caras a cada arista y aristas a cada vértice. Fuente: Producción propia 
Abordaje del diseño bioinspirado en las formas, los sistemas y los procesos de la naturaleza

Es corriente afirmar que los panales de abejas son una demostración del conocimiento que tienen estos insectos sobre geometría y teselado del espacio.

Realmente, el panal de abejas (Figura 10) es un emocionante caso de organización del espacio.

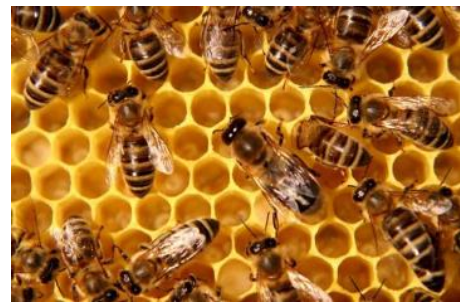

Figura 10: Panal de abejas. Fuente: https://howtodoright.com/where-do-honey-bees-live/

Sin embargo, la abeja es un insecto que sólo actúa respondiendo a ciertos códigos genéticos que la naturaleza le impuso. Carece por completo de conocimientos de geometría.

Construye las celdas que albergarán las larvas y la miel, en forma de pequeños cilindros, utiliza sus antenas como medida, y emplea para la construcción la cera que ella misma produce.

Mientras la cera se mantiene caliente está blanda y moldeable, y de este modo va acomodando las celdas unas con otras.

Lo realmente genial de esta construcción no es precisamente su distribución hexagonal, que en definitiva es la consecuencia del acomodamiento de la cera blanda en los encuentros, sino la selección natural de un modelo de ordenamiento que deja el menor intersticio entre las celdas adyacentes y, por consiguiente, el cumplimiento fiel y estricto de esas dos leyes básicas y fundamentales de la naturaleza: la economía de la sustancia y el mínimo esfuerzo.

Así como la esfera, representada por una pompa de jabón en el espacio, es la respuesta más económica al equilibrio de las tensiones internas contenidas en un volumen máximo, la circunferencia representa en el plano, para una determinada superficie, la respuesta más económica a las tensiones internas contenidas en una superficie máxima para un determinado perímetro.

Cuando se trata de llenar el espacio partiendo de una circunferencia, la propiedad de isotropía que estaba presente cuando fue considerada individualmente, ya no es posible lograr debido a su incapacidad para llenar por sí sola el espacio sin dejar intersticios. Esta incapacidad no significa que no puedan desarrollarse tramas a partir de circunferencias, por el contrario, se puede establecer perfectamente un sinnúmero de combinaciones de circunferencias entre sí (Figura 11).
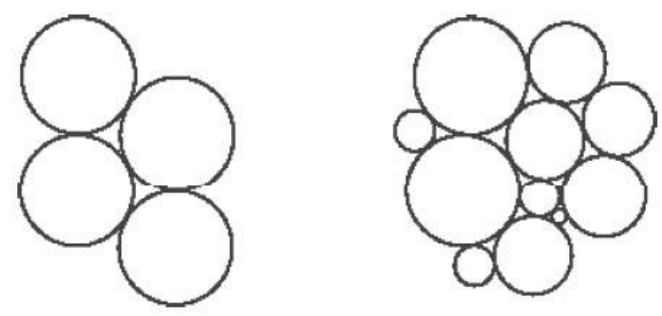

Figura 11: Distintas formas de componer circunferencias anexadas. Fuente: Producción propia

Cuando se trata de organizaciones con circunferencias iguales, el problema se reduce a dos alternativas; la $1^{\text {a }}$ con una circunferencia central y otras 6 adyacentes Figura 12), ordenadas según tres direcciones, y la $2^{\mathrm{a}}$ con una circunferencia central y otras 4 adyacentes (Figura 13), a las que se adicionan otras 4 más, adyacentes a estas últimas, ordenadas en dos direcciones. 
Vedoya

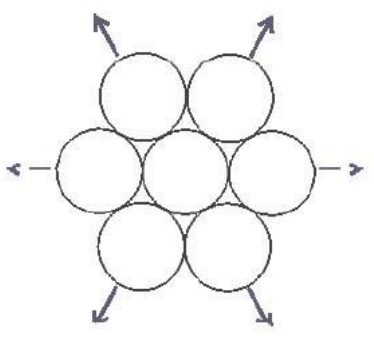

Figura 12: Ordenamiento según 3 direcciones

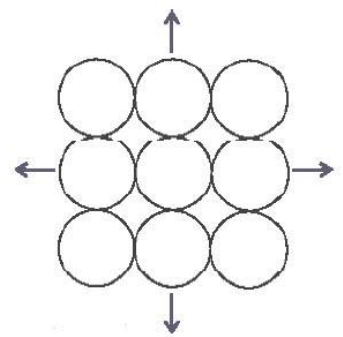

Figura 13: Ordenamiento según 2 direcciones Fuente: Producción propia

En los dos casos mencionados se producen espacios intersticiales; en el primero, con tres lados curvos Figura 14), y en el segundo con cuatro (Figura 15).

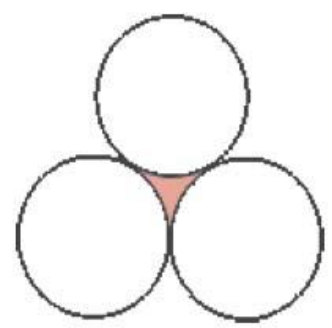

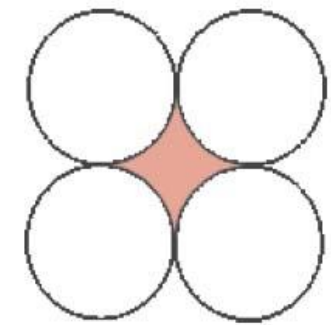

Figura 15: Intersticios de cuatro lados curvos

Figura 14: Intersticio de tres lados curvos

Fuente: Producción propia

En cada circunferencia de estas tramas, existen tensiones que pugnan por expandir el espacio interior, fuerzas que son contenidas por las circunferencias adyacentes, en el punto de contacto. A medida que se aleja del punto de contacto, se podrá observar que comienza a deformarse bajo la acción de aquella tensión. Como la circunferencia es la respuesta de equilibrio a las tensiones que se producen en su interior en forma uniforme (isotropía), al ser iguales entre sí las circunferencias que integran la trama, sus tensiones también lo serán, pues de otro modo las respuestas hubieran sido diferentes.

Consecuentemente, las deformaciones debidas a dichas tensiones serán uniformes (considerando que hay tensiones externas que actúan hacia el interior de la trama). En el punto de contacto de una circunferencia con la adyacente, las tensiones internas en ambas son iguales $y$, por lo tanto, se anulan mutuamente (Figura 16). No obstante, en la zona del intersticio, como ahí no existe tensión alguna que actúe, la circunferencia tenderá a aplastarse hasta llegar a cubrir dicho espacio (Figura 17), equilibrándose con la adyacente.
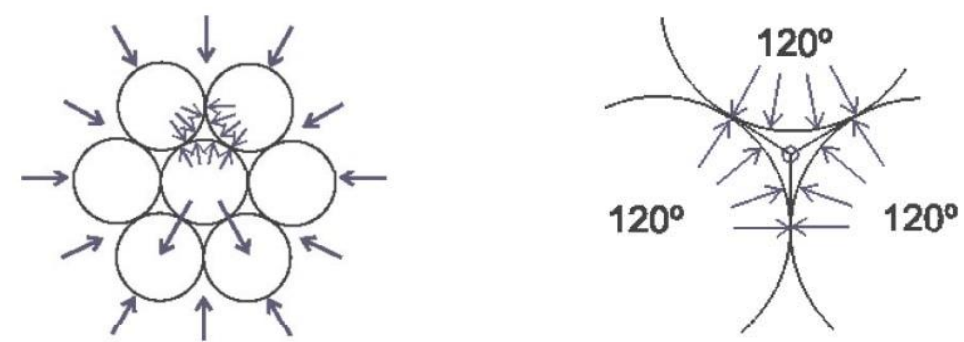

Figura 16: Las tensiones se anulan en los puntos de contacto Figura 17: Las tensiones tienden a deformar la superficie Fuente: Producción propia 
Abordaje del diseño bioinspirado en las formas, los sistemas y los procesos de la naturaleza

Esta deformación continuará hasta cubrir totalmente el hueco y convertir las curvas en líneas rectas. Los ángulos que se forman en el punto de incidencia de las tres circunferencias, por tratarse de una deformación uniforme, debida a tensiones iguales, serán también iguales entre sí. Como se trata de tres ángulos iguales que dividen a la circunferencia de $360^{\circ}$, cada uno valdrá $120^{\circ}$, que es precisamente el valor del ángulo interior en los vértices de un hexágono regular (Figura 18).

La respuesta de equilibrio a las tensiones externas que actúan uniformemente en todas las direcciones posibles sobre una trama de circunferencias como en los ejemplos dados, es precisamente una trama hexagonal. El hexágono representa la máxima adaptación isotrópica correspondiente a una trama que tesela totalmente el espacio, sin dejar huecos. Como en este caso particular se ha trabajado con una sola variedad de figura, el hexágono, el conjunto logrado se dice que es una equipartición del espacio (Vedoya y Hermida, 2013).

Decirlo con palabras y gráficos elaborados puede resultar interesante pero no verosímil. No obstante, las leyes físicas son inalterables y demuestran una vez más que esto es así.

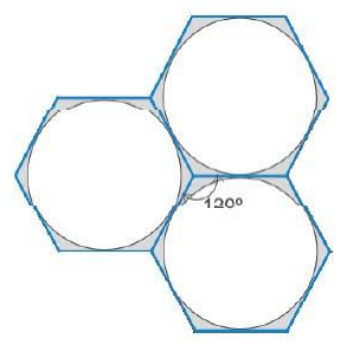

Figura 18: Conformación hexagonal como resultado de la deformación. Fuente: Producción propia

Para ello, las pompas de jabón ponen nuevamente de manifiesto la presencia de esas dos leyes fundamentales, del mínimo esfuerzo y de economía de la sustancia (Figuras 19 a 25).
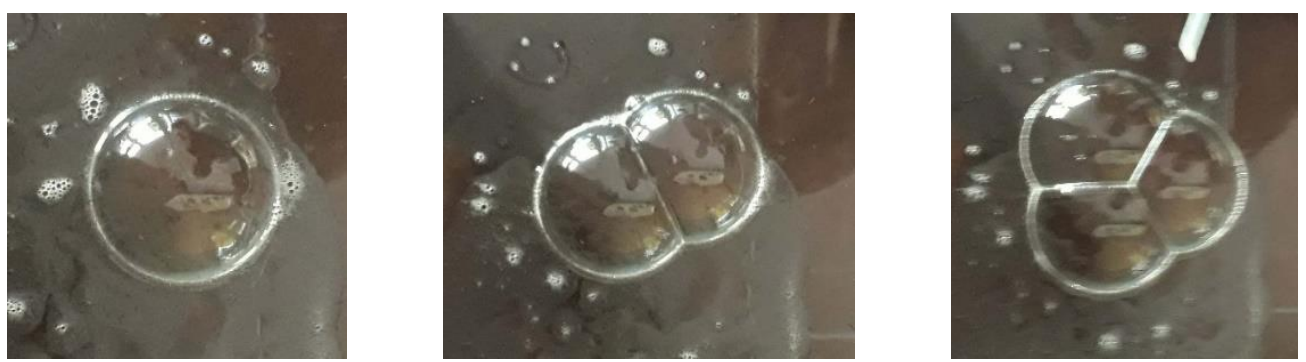

Figuras 19 a 21: Proceso de integración desde una a 2 y 3 pompas. Fuente: Producción propia
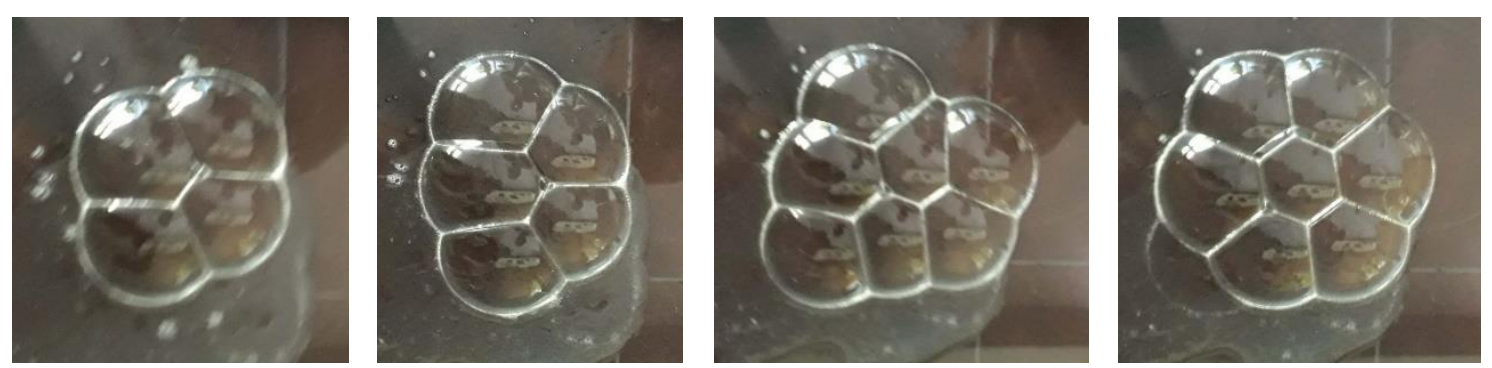

Figuras 22 a 25: Proceso de integración de 4, 5, 6 y 7 pompas. Fuente: Producción propia

Nótese la forma hexagonal adoptada por la pompa central, encerrada por las otras seis. 
Abordaje del diseño bioinspirado en las formas, los sistemas y los procesos de la naturalezal.

Vedoya

La Trama hexagonal es una constante en innumerables ejemplos que nos brinda la naturaleza, como el ordenamiento, también según una trama hexagonal, de los ocelos en el ojo complejo de una mosca (Figura 26).

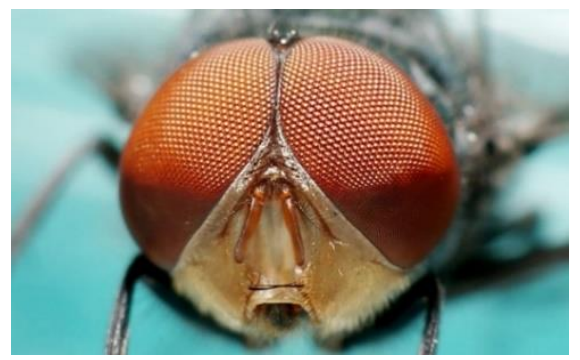

Figura 26: Ojo complejo de una mosca. Fuente: https://es.calcuworld.com/cuantos/cuantos-ojos-tiene-una-mosca/

O también el esquema que se destaca en el caparazón de una tortuga (Figura 27).

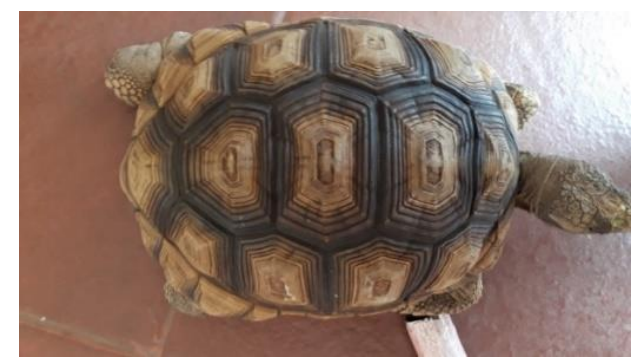

Figura 27: Diseño hexagonal del caparazón de una tortuga. Fuente: Producción propia

La trama hexagonal es consecuencia de la ley de mínimo esfuerzo, donde se comprueba que a un nudo, sólo concurren tres, y nada más que tres nervios, como sucede con los nervios que soportan el ala de una libélula (Figura 28).

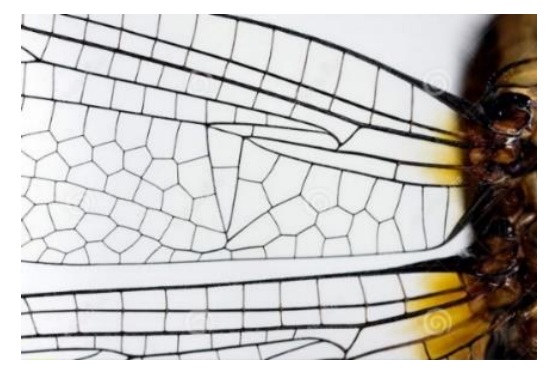

Figura 28: Detalle del ala de una libélula- Fuente: https://es.dreamstime.com/imagen-de-archivo-libre-de-regalías-alade-la-libélula-image18603906

Un caso especial de organización se encuentra en el ordenamiento en espiral de algunos vegetales, como la flor del girasol (Figura 29), donde pueden contarse 21 espirales en un sentido, y 34 en el sentido contrario, dos números consecutivos de la serie de Fibonacci. 


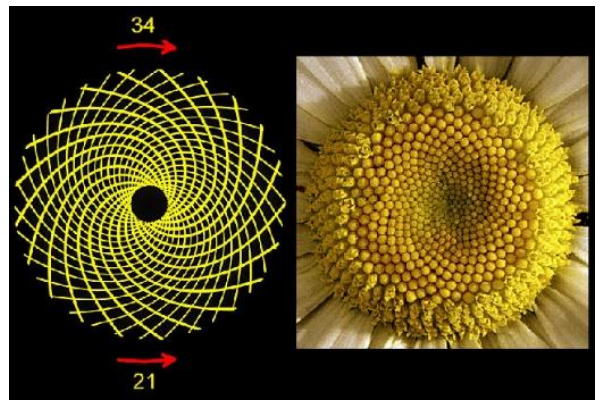

Figura 29: Flor del girasol. Fuente: https://www.publicitarioscriativos.com/mitos-e-verdades-por-tras-da-proporcaoaurea/

Arquímedes de Siracusa (s. III a.C.) fue quizá uno de los matemáticos más importantes de la antigüedad. Es recordado por sus numerosos inventos y propuestas, como el tornillo que lleva su nombre, y el principio, también con su nombre, que refiere a la relación entre el volumen de un líquido que desplaza un cuerpo sumergido en él, y el peso de éste.

Es destacable su descubrimiento en el campo de la geometría, que parte de los cinco poliedros regulares, conocidos como "sólidos platónicos" en homenaje a Platón, a los que divide sus aristas en dos y tres partes respectivamente, obteniendo otros poliedros compuestos por dos o tres polígonos regulares de distinta especie. Aplicando el mismo procedimiento a estos nuevos poliedros, obtiene en total trece nuevos cuerpos geométricos que se conocen como "poliedros semiregulares" o "arquimedianos", en homenaje a su descubridor.

De estos trece poliedros interesa particularmente para este trabajo uno compuesto por doce pentágonos y treinta hexágonos, resultante de dividir en tres cada arista de un icosaedro regular, que se conoce con el nombre de "icosaedro truncado" (Figura 30).

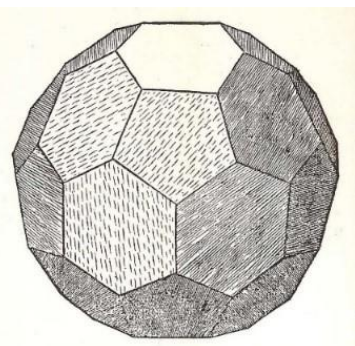

Figura 30: Icosaedro truncado. Fuente: Imagen de Leonardo da Vinci que ilustra el libro "La divina proporción” de Fr. Luca Pacioli (1509)

Debido a la propiedad de estos poliedros arquimedianos de estar inscriptos en una esfera, el icosaedro truncado ha servido de base para el diseño y construcción del balón de fútbol (Figura $31)$.

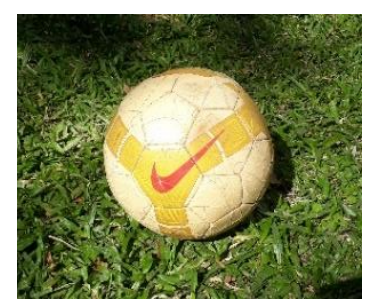

Figura 31: Balón de fútbol. Fuente: Producción propia 
Vedoya

Todo esto dicho para concluir que siempre la naturaleza se ha anticipado a la ciencia, y para este caso, la relación se encuentra en el carbono.

El carbono presenta tres formas alotrópicas: grafito, diamante y fullerenos. El fullereno es llamado también "buckminsterfullereno", en homenaje al Arq. Buckminster Füller, por sus numerosas construcciones basadas en formas geodésicas constituidas por barras y nudos.

Existen varias manifestaciones de fullerenos, pero el que interesa acá es el que se identifica con la sigla C-60.

El C-60 es una molécula compleja, formada por 60 átomos de carbonos distribuidos en una red de doce pentágonos y treinta hexágonos, que recuerda precisamente al icosaedro truncado (Figura32).

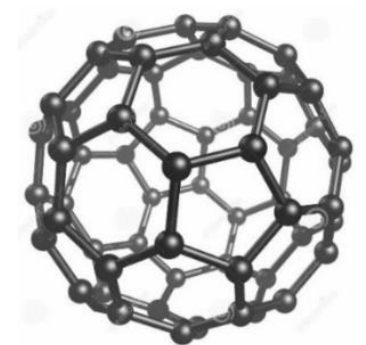

Figura 32: Fullreno C-60. Fuente: https://es.dreamstime.com/foto-de-archivo-fullerene-c60-image23786180

La invención de la rueda presenta confusos datos respecto tanton de su creador como de la fecha en que aconteció. Existen indicios de su existencia en inscripciones sumerias que datan de ca. 2.500 a.C.

Tampoco está probado si su uso se inició para el transporte o para el torno del alfarero. Lo cierto es que ha servido de base de innumerables productos derivados: engranajes, tornillos y tuercas, poleas, rotores, etc.

Aquí nuevamente la naturaleza ha sido pionera en la producción de estos objetos.

Las bacterias, microorganismos procariotas, relativamente sencillos, de unos $2 \mu \mathrm{m}$ de ancho y entre 0,5 y $5 \mu \mathrm{m}$ de largo, cuya existencia se remonta a aproximadamente 4.200 millones de años, poseen un filamento o flagelo que, con su vibración, les permite desplazarse.

La vibración del flagelo bacteriano se logra mediante un complicado mecanismo interior de la bacteria (Figura 33), compuesto por un rotor que gira entre 6.000 y 17.000 rpm (Vedoya, 2017).

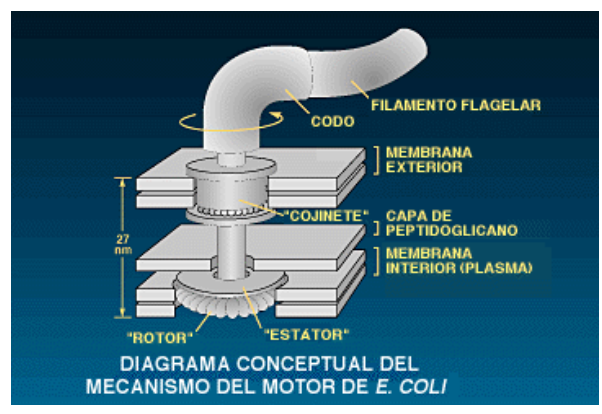

Figura 33: Esquema del mecanismo complejo del flagelo bacteriano.

Fuente: http://www.sedin.org/propesp/flagellum.htm

Por otra parte, la naturaleza también se ha anticipado en la producción de engranajes, tuercas y tornillos, etc. como se verá en los siguientes ejemplos. 
Abordaje del diseño bioinspirado en las formas, los sistemas y los procesos de la naturaleza

El issus coleoptratus es un insecto del grupo de los fulgomorfos, que salta distancias muy superiores a las de otros insectos, en relación con su tamaño, de aproximadamente $1 \mathrm{~mm}$. En su estado de ninfa posee un sistema de engranajes instalados en su cadera, de unos 20 micrones, que le permiten deslazarse a los saltos (Vedoya, 2017). Este sistema va desapareciendo a medida que adopta la forma adulta (Figura 34).

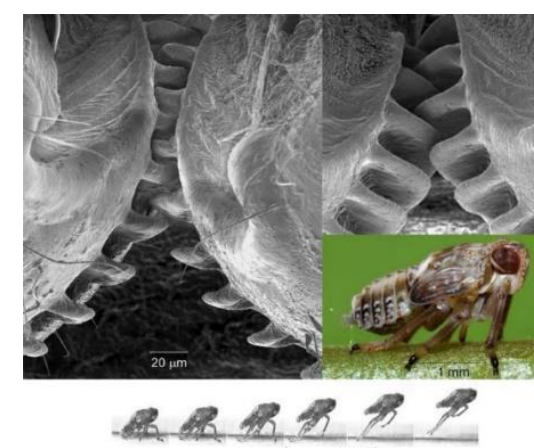

Figura 34: Issus coleoptratus y detalle del engranaje de la cadera. Fuente: https://es.slideshare.net/manquiros/biomimesis-y-sostenibilidad

El mecanismo de tuerca y perno generalmente se emplea para fijar un objeto a otro. Este mismo mecanismo también lo emplea cierta especie de gorgojo, el trigonopterus oblongus (Vedoya, 2017), que une sus extremidades al cuerpo de forma similar, a diferencia de lo que sería común en otros insectos que poseen articulación por rótula (Figuras 35 a 37).

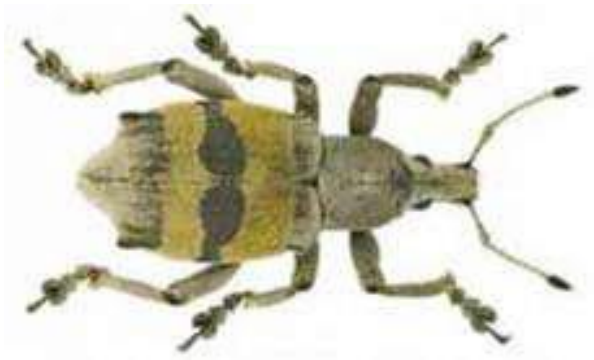

Figura 35: Trigonopterus oblongus. Fuente: https://whyfiles.org/2011/biology-as-engineer/index.html

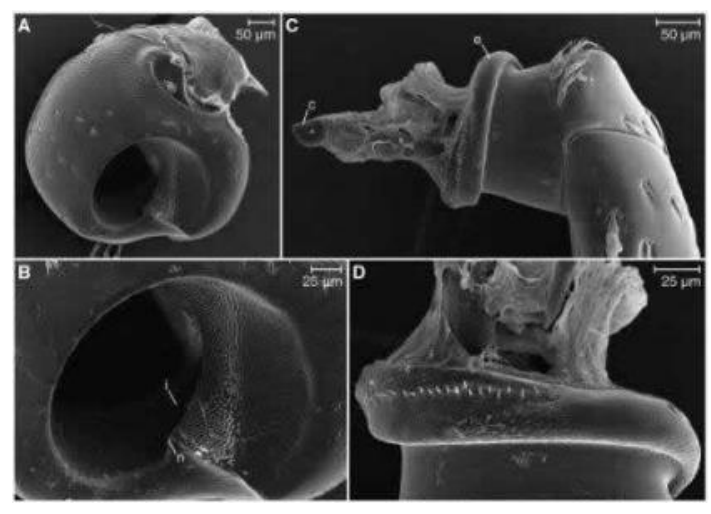

Figura 36: Vista aumentada del Sistema de articulación

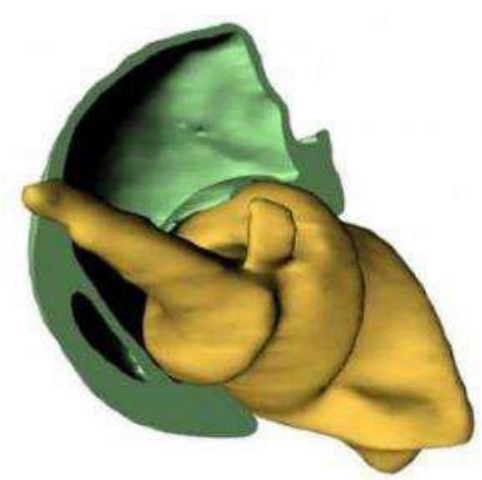

Figura 37: Detalle del encastre en la cadera Fuente: https://phys.org/news/2011-07-papuan-weevil-screw-in-legs.html 
Vedoya

\section{REFLEXIONES FINALES}

La naturaleza es una emocionante enciclopedia que se ofrece a todo quién se interese en abrirla y recorrer sus páginas.

Allí encontrará todas las respuestas que satisfagan sus interrogantes. Sólo deberá formular la pregunta adecuada para resolver cada problema que se le presente.

Comprender a la naturaleza y aprender de ella implica analizarla en su conjunto, a partir de sus formas, profundizando en los sistemas que las sustentan, considerando todos los procesos que generan la interrelacion entre las especies.

Un diseño que pretenda ser biomimético debiera aprender del árbol, que es al mismo tiempo, sombra, alimento, cobijo, fertilizante del suelo y subsuelo, a la vez que consume el dióxido de carbono, emite el oxígeno que sustenta la vida, al tiempo que produce su propio alimento mediante el proceso de fotosíntesis.

\section{BIBLIOGRAFÍA}

Pacioli, Luca (1509): La divina proporción - Editado en Buenos Aires (Argentina), por Editorial Losada (1946)

Vedoya, Daniel E, et al (2020): Aprendiendo de la naturaleza desde los procesos - En Revista ARQUITECNO 11, págs. 47 a 51. Corrientes (Argentina): Ediciones del ITDAHu, junio de 2018

Vedoya, Daniel E. y Hermida, María del C. (2013): Principios básicos para la estructuración del espacio - Corrientes (Argentina): Ediciones del ITDAHu - ISBN: 978-987-25052-7-1 
